\title{
Severe complication of pulmonary vein angiography
}

Sir,

We suggest that the complication described by Alpert and Culham on p. 727 of this issue can be avoided by a less wedged position of the catheter tip than that evidently used in this instance, and that a preliminary hand injection to check the suitability of the position is advisable. Extravasation is certainly not an essential for flow into the pulmonary arteries to occur and we aim to avoid it. While low pressures can sometimes produce the desired result, it is our experience that a pressure injection is more likely to give demonstration of the more central parts of the pulmonary arterial tree. It is important to withdraw the catheter immediately the injection is completed.

S. P. Singh and R. Astley, The Children's Hospital, Ladywood Middleway, Ladywood, 일 Birmingham B16 8ET. 